\title{
Preparation and characterization of porous NiO thin films through thermal decomposition of Ni-containing metal organic framework thin layers
}

\author{
Yuya TAKEDA ${ }^{1}$, Yuta MATSUSHIMA ${ }^{1}$ and Hidero UNUMA ${ }^{1, \dagger}$ \\ ${ }^{1}$ Graduate School of Science and Engineering, Yamagata University, 4-3-16 Jonan, Yonezawa, Yamagata 992-8510, Japan
}

We report herein that porous and electrochemically active $\mathrm{NiO}$ thin films were prepared through the deposition and thermal decomposition of a Nickel-containing metal organic framework. First, $\mathrm{Ni}_{3}\left(\mathrm{HCOO}_{6}\right.$ thin film layers were deposited on an electrically conductive substrate, then the layers were thermally decomposed into $\mathrm{NiO}$ in a temperature range from 543 to $673 \mathrm{~K}$. The electrochemical response of the resultant $\mathrm{NiO}$ thin films was highest when the thermal decomposition temperature was as low as $543 \mathrm{~K}$. The cylcic voltammetry revealed that the current response of the present thin film with the highest performance was twice larger than a previously reported one. The deposition of a $\mathrm{Ni}_{3}(\mathrm{HCOO})_{6}$ thin film by a chemical bath technique followed by thermal decomposition may be a facile and promising route to obtain binder-free, porous metal oxide layers for electrochemical applications.

(O2019 The Ceramic Society of Japan. All rights reserved.

Key-words : Nickel oxide, MOF, Thin films

[Received June 5, 2019; Accepted July 4, 2019]

Nickel oxide have been studied as a potential candidate for the active substance used in supercapacitors, ${ }^{1)-7)}$ chemical and optical sensors, ${ }^{8)-12}$ ) and electrochromic devices. ${ }^{13)-20)}$ In these applications of electrochemical devices, the nickel oxide is better to be highly porous because the main chemical reactions take place at the interface between solid-liquid interface of solid nickel oxide and the electrolyte solutions. Recently, especially in the last decade, many efforts have been devoted to the morphology control and synthesis of nickel oxide powders and thin films. In order to synthesize nickel oxide while controlling the microstructure of the product, so-called liquid phase synthesis is advantageous because a large variety of morphology can be endowed with the resultant nickel oxide. For example, sol-gel method, 3),18) biotemplating, ${ }^{6)}$ hydrothermal, ${ }^{11)}$ and chemical bath methods ${ }^{4), 5), 14)-16), 19)-23)}$ as well as electrodeposition. ${ }^{17)}$

An extensive attention is being paid to a series of compounds which are called metal-organic framework (MOF), in which metal ions are connected by two- or threefunctional ligands into highly ordered polymer structure. MOFs themselves exhibit unique functions. At the same time, MOFs can be good precursors of finely and highly porous metal oxides. ${ }^{24)-26)}$ Metal ions are separated far from each other in MOFs by the bulky, organic crosslinking ligands. When the organic ligands are decomposed

\footnotetext{
Corresponding author: H. Unuma; E-mail: unuma@yz. yamagata-u.ac.jp
}

temperatures below $700 \mathrm{~K}$, the inorganic residues can be fluffy and low-density bodies before being sintered densely. For example, Wang et al. ${ }^{25)}$ prepared mesoporous $\mathrm{NiO}$ by decomposing $\mathrm{Ni}_{3}(\mathrm{btc})_{2} \cdot 12 \mathrm{H}_{2} \mathrm{O} \quad$ (btc $=1,3,5-$ benzenetricarboxylic acid) at $673 \mathrm{~K}$, and $\mathrm{Han}$ et al. ${ }^{26)}$ obtained porous $\mathrm{NiO}$ powders by calcining $\mathrm{Ni}_{3}(\mathrm{HCOO})_{6}$ at the same temperature to investigate the electrochemical properties of the resultant $\mathrm{NiO}$.

MOF powders can be synthesized without very much difficulty: under mild conditions from organic-water mixed solvents. When MOFs are synthesized to be served the precursors of the porous thin films of metal oxides, however, the MOFs have to be deposited onto pertinent substrates. A number of works have been published on the deposition of MOF thin films from aqueous solutions at room temperature (Zn-2-methylimidazol MOF), ${ }^{27)}$ by the electrodeposition (Eu-HBPTC MOF) ${ }^{28)}$ or heteroepitaxial method $\left[\mathrm{Cu}_{3}(\mathrm{BTC})_{2} \mathrm{MOF}\right]{ }^{29), 30)}$ In order to facilitate the heterogeneous nucleation on the substrates immersed in a solution while suppressing the homogeneous nucleation, the composition of the starting solution should be controlled so that the rate or MOF formation does not become so rapid. ${ }^{31)}$ In any case, since the formation condition differs from MOF to MOF, the optimum condition of the thin film deposition of a MOF from an aqueous solution has to be found by trial and error.

As far as Ni-containing MOFs are concerned, MOFs with aspartic acid and 4,4'-bipyridine ${ }^{32), 33)}$ or those with malic acid and 4,4'-bipyridine ${ }^{34)}$ have been synthesized 
under solvothermal conditions. In this study, a Ni-oxalate MOF, which can be formed under milder conditions, ${ }^{26)}$ was selected as the thin film substance. Porous $\mathrm{NiO}$ thin films were obtained through thermal decomposition of the Ni-oxalate MOF. The evolution of the crystalline phases, microstructure, and electrochemical performance was investigated as a function of the heat-treatment temperature.

Substrates were glass slides coated with F-doped tin oxide (FTO glass, $1.8 \mathrm{~mm} \times 20 \mathrm{~mm} \times 40 \mathrm{~mm}$, AGC fabritech Co., Ltd., Tokyo, Japan). The substrates had been cleaned with a detergent and immersed in a $\mathrm{H}_{2} \mathrm{O}_{2}-\mathrm{HNO}_{3}$ mixed solution (1:1 by volume) for a few days. Chemical reagents were purchased from Kanto Chemical Co., Inc. Nickel nitrate hexahydrate $\left(0.12 \mathrm{~mol} / \mathrm{dm}^{3}\right)$ and oxalic acid $\left(0.73 \mathrm{~mol} / \mathrm{dm}^{3}\right)$ were dissolved in $\mathrm{N}, \mathrm{N}^{\prime}$-dimethylfolmamide (DMF). Into a PFA vessel (PFA: copolymer of tetrafluoroethylene and perfluoroalkoxyethylene, $20 \mathrm{~cm}^{3}$ ) was added $8 \mathrm{~cm}^{3}$ of the DMF solution and a piece of FTO glass. The vessel was placed in an electric oven kept at $353 \mathrm{~K}$ for $24 \mathrm{~h}$. An opaque thin film light green in color was obtained together with powder precipitate. The thin film and the precipitate were separately heat-treated in an oxygen flow at temperatures from 543 to $673 \mathrm{~K}$ for $3 \mathrm{~h}$.

The heat-treated precipitates were subjected to X-ray diffraction (XRD) analysis (Miniflex, Rigaku, Tokyo, Japan). The heat-treated thin films were observed with a scanning electron microscope (SEM, e-SEM, Shimadzu Rika Corp., Tokyo, Japan). The electrochemical property of the thin films was investigated by the cylcic voltammetry in two electrolyte solutions: an aqueous solution containing $6 \mathrm{~mol} / \mathrm{dm}^{3} \mathrm{KOH}$ and a propylene carbonate solution containing $1 \mathrm{~mol} / \mathrm{dm}^{3}$ of $\mathrm{LiClO}_{4}$. These electrolyte solutions were selected because these are commonly used for the electrochemical characterization of $\mathrm{NiO}$ thin films. A platinum wire and an $\mathrm{Ag} / \mathrm{AgCl}$ electrode were used for the counter and reference electrodes, respectively. The scanning rate was controlled at $50 \mathrm{mV} / \mathrm{s}$ with a potentio-galvano stat (Versastat 3, Hokuto Denko Corp., Tokyo, Japan). After all the measurements, the thin films were dissolved in diluted $\mathrm{HNO}_{3}$ and the solutions were

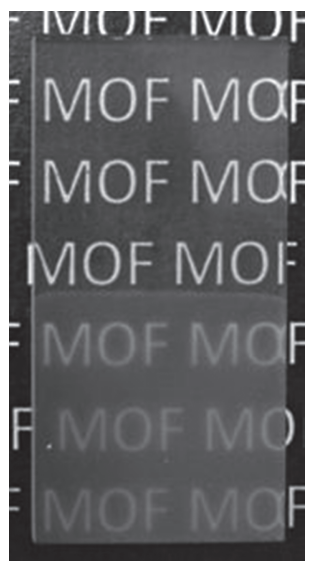

Fig. 1. Appearance of an as-deposited $\mathrm{Ni}_{3}(\mathrm{HCOO})_{6}$ thin film (lower half) on an FTO-coated glass slide. quantitatively analyzed for Ni.

Figure 1 shows visual appearance of an as-deposited thin film. When the deposition temperature was higher than $553 \mathrm{~K}$, powdery precipitate predominated and the thin films were prone to detach. The deposition was very late when the deposition was conducted at lower temperatures than $543 \mathrm{~K}$.

Figure 2 shows the XRD profiles of the thin films before and after heat-treatments. The diffraction pattern of as-deposited film showed good agreement with that of $\mathrm{Ni}_{3}(\mathrm{HCOO})_{6} \cdot{ }^{26)}$ Heat-treatments at temperatures from 543 to $573 \mathrm{~K}$ resulted in $\mathrm{NiO}$ with a small amount of metallic $\mathrm{Ni}$. The amount of metallic Ni decreased with increasing heat-treatment temperature. The deposition of metallic nickel, despite heat-treatment under an oxygen atmosphere, may be caused by the reduction of $\mathrm{Ni}^{2+}$ upon decomposing the oxalate ligand.

Figure 3 shows cylcic voltammograms of the thin films heat-treated at various temperatures. The vertical axis is the current density, that is, the current per mass of nickel ions in the thin films. The redox reactions involved in $\mathrm{KOH}$ aqueous solution and $\mathrm{LiClO}_{4}$ solution are indicated in Eqs. (1) and (2): ${ }^{16)}$

$$
\begin{aligned}
& \mathrm{NiO}+\mathrm{OH}^{-} \leftrightarrows \mathrm{NiOOH}+\mathrm{e}^{-} \\
& \mathrm{NiO}+\mathrm{xe}^{-} \leftrightarrows \mathrm{Li}_{x} \mathrm{NiO}
\end{aligned}
$$

It should be noted that, the lower the heat-treatment temperature was, the higher the current density was. The current density at the reduction peak of the thin film heattreated at $553 \mathrm{~K}(-30 \mathrm{~A} / \mathrm{g}$ at $-0.1 \mathrm{~V})$ was twice higher than that reported by Han et al. $\left.{ }^{26}\right)(-10 \mathrm{~A} / \mathrm{g}$ at $+0.35 \mathrm{~V})$ although the present peak appeared at more negative potential. The higher current response exhibited by the present thin film may be due to the absence of organic binders which inhibits the electron transport.

The dependence of the current response on the heattreatment temperature is likely to be attributed to the change of the porous structure, according to the previous works. ${ }^{24)-26)}$ To certify that, as-deposited and heat-treated thin films were examined by SEM. Figure 4 shows those micrographs. The as-deposited thin film consisted of

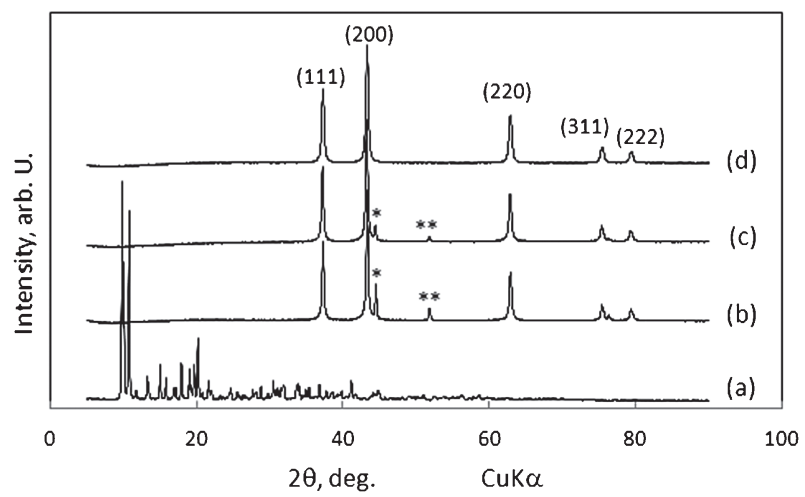

Fig. 2. XRD profiles of (a) as-deposited and heat-treated at (b) 543, (c) 573, and (d) $673 \mathrm{~K}$. Indices represent those of NiO. The peaks marked $*$ and $* *$ are those of Ni. 

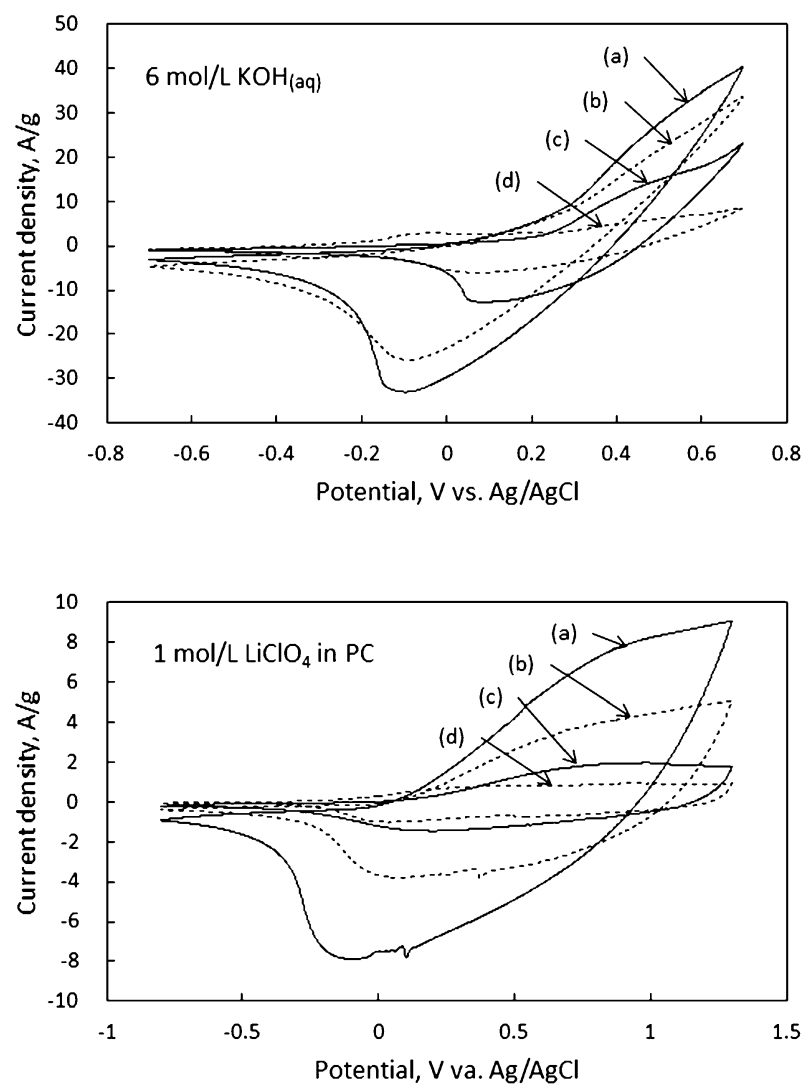

Fig. 3. Cyclic voltammograms of $\mathrm{NiO}$ thin films heat-treated at (a) 543 , (b) 553 , (c) 573 , and (d) $673 \mathrm{~K}$ in two different electrolyte solutions.

grains approximately $5 \mu \mathrm{m}$ in size and with smooth facets. After a heat-treatment at $553 \mathrm{~K}$, the grains seemed to have shrunk to those $1 \mu \mathrm{m}$ in size, like deflated balloons. Then, after a heat-treatment at $673 \mathrm{~K}$, the $\mathrm{NiO}$ particles sintered one another, leaving $\mathrm{NiO}$ agglomerates and exposure of the substrate surface. In Fig. 4(c), the exposed surface was indicated as "FTO".

It may be reasonable to assume that, upon the decomposition of MOF, bulky oxalate ligands were liberated leaving fluffy and highly porous $\mathrm{NiO}$ framework, and then at $553 \mathrm{~K}$, the $\mathrm{NiO}$ framework should have partially sintered to porous particles. As long as the heat-treatment for the decomposition of MOF is not too high, the resultant $\mathrm{NiO}$ should possess a high surface area where the interfacial electrochemical reactions to proceed. As the heattreatment temperature is raised further, the previously porous $\mathrm{NiO}$ particles sinter into dense particles whose surface area is low.

The coexistence of metallic Ni may be responsible for better current response, as $\mathrm{Li}$ et al. ${ }^{35)}$ pointed out that the dispersion of $\mathrm{Ni}$ nanoparticles in $\mathrm{NiO}$ thin films improved the electrochemical response through the formation of migration path of electrons. In the present case, however, the effect of metallic nickel on the electrochemical response is unclear because the amount seemed to be very small.

In summary, this work clarified an appropriate condition for the deposition of $\mathrm{Ni}_{3}(\mathrm{HCOO})_{6}$ thin films by a chemical


Fig. 4. SEM pictures of the film surfaces of (a) as-deposited and heat-treated at (b) 553 and (c) $673 \mathrm{~K}$. In (c), "FTO" indicate the areas of the bare surface of the substrate.

bath method, and then the thin films were heat-treated in a flow of $\mathrm{O}_{2}$ to convert the MOF layers to porous $\mathrm{NiO}$ thin films. The heat-treatment temperature was desired to be as low as possible to obtain electrochemically active $\mathrm{NiO}$ thin films.

\section{References}

1) M. M. Sk, C. Y. Yue, K. Ghosh and R. K. Jena, J. Power Sources, 308, 121-140 (2016).

2) R. S. Kate, S. A. Khalate and R. J. Deokate, J. Alloy. 
Compd., 734, 89-111 (2018).

3) M. Wu, J. Gao, S. Zhang and A. Chen, J. Porous Mat., 13, 407-412 (2006).

4) A. I. Inamdar, Y. S. Kim, S. M. Pawar, J. H. Kim, H. S. Im and H. S. Kim, J. Power Sources, 196, 2393-2397 (2011).

5) Y. Q. Zhang, X. H. Xia, J. P. Tu, Y. J. Mai, S. J. Shi, X. L. Wang and C. D. Gu, J. Power Sources, 199, 413417 (2012).

6) J. He, Y. Zhao, D. B. Xiong, W. Ran, J. Xu, Y. Ren, L. Zhang, Y. Tang and F. Gao, Mater. Lett., 128, 117-120 (2014).

7) M. Kundu and L. Liu, Mater. Lett., 144, 114-118 (2015).

8) A. M. Soleimanpour and A. H. Jayatissa, Mater. Sci. Eng., C, 32, 2230-2234 (2012).

9) P. Wu, J. H. Sun, Y. Y. Huang, G. F. Gu and D. G. Tong, Mater. Lett., 82, 191-194 (2012).

10) G. Wang, X. Lu, T. Zhai, Y. Ling, H. Wang, Y. Tong and Y. Li, Nanoscale, 4, 3123-3127 (2012).

11) G. Zhu, H. Xu, Y. Liu, C. Xi, J. Yang, X. Shen, J. Zhu and J. Yang, J. Colloid Interf. Sci., 412, 100-106 (2013).

12) H. B. Shim, W. Y. Kim, I. K. Kang and H. C. Lee, IEEE Sens. J., 17, 6522-6528 (2017).

13) G. A. Niklasson and C. G. Granqvist, J. Mater. Chem., 17, 127-156 (2007).

14) M. A. Vidales-Hurtado and A. Mendoza-Galván, Solid State Ionics, 179, 2065-2068 (2008).

15) X. H. Xia, J. P. Tu, J. Zhang, X. L. Wang, W. K. Zhang and H. Huang, Sol. Energy Mater. Sol. Cells, 92, 628633 (2008).

16) H. Huang, J. Tian, W. K. Zhang, Y. P. Gan, X. Y. Tao, X. H. Xia and J. P. Tu, Electrochim. Acta, 56, 42814286 (2011).

17) Y. F. Yuan, X. H. Xia, J. B. Wu, Y. B. Chan, J. L. Yang and S. Y. Guo, Electrochim. Acta, 56, 1208-1212 (2011).

18) S. H. Park, J. W. Lim, S. J. Yoo, I. Y. Cha and Y. E.
Sung, Sol. Energy Mater. Sol. Cells, 99, 31-37 (2012).

19) Z. Chen, A. Xiao, Y. Chen, C. Zuo, S. Zhou and L. Li, J. Phys. Chem. Solids, 74, 1522-1526 (2013).

20) A. C. Nwanya, S. U. Offiah, I. C. Amaechi, S. Agbo, S. C. Ezugwu, B. T. Stone, R. U. Osuji, M. Maaza and F. I. Ezama, Electrochim. Acta, 171, 128-141 (2015).

21) Q. Y. Li, R. N. Wang, Z. R. Nie, Z. H. Wang and Q. Wei, Colloid Interf. Sci., 320, 254-258 (2008).

22) M. A. Vidales-Hurtado and A. Mendoza-Galván, Mater. Chem. Phys., 107, 33-38 (2008).

23) S. Y. Han, D. H. Lee, Y. J. Chang, S. O. Ryu, T. J. Lee and C. H. Chang, J. Electrochem. Soc., 153, C382C396 (2006).

24) A. Indra, T. Song and U. Paik, Adv. Mater., 30, 1705146 (2018).

25) D. Wang, W. Ni, H. Pang, Q. Lu, Z. Huang and J. Zhao, Electrochim. Acta, 55, 6830-6835 (2010).

26) Y. Han, S. Chang, N. Shen, D. Li and X. Li, Mater. Lett., 188, 1-4 (2017).

27) G. Lu, O. K. Farha, W. Zhang, F. Huo and J. T. Hupp, Adv. Mater., 24, 3970-3974 (2012).

28) H. Liu, H. Wang, T. Chu, M. Yu and Y. Yang, J. Mater. Chem. C, 41, 8683-8690 (2014).

29) P. Falcaro, K. Okada, T. Hara, K. Ikigaki, Y. Tokudome, A. W. Thornton, A. J. Hill, T. Williams, C. Doonan and M. Takahashi, Nat. Mater., 16, 342-348 (2017).

30) K. Ikigaki, K. Okada, Y. Tokudome and M. Takahashi, J. Sol-Gel Sci. Techn., 89, 128-134 (2019).

31) H. Unuma, J. Ceram. Soc. Jpn., 121, 919-924 (2013).

32) Y. Zhou, J. Li, S. Wang, J. Zhang and Z. Kang, J. Mater. Sci., 52, 12089-12097 (2017).

33) S. Wang, Z. Kang, B. Xu, L. Fan, G. Li, L. Wen, X. Xin, Z. Xiao, J. Pang, X. Du and D. Sun, Inorg. Chem. Commun., 82, 64-67 (2017).

34) Q. Li, G. Liu, K. Huang, J. Duan and W. Jin, Asia-Pac. J. Chem. Eng., 11, 60-69 (2016).

35) X. Li, A. Dhanabalan and C. Wang, J. Power Sources, 196, 9625-9630 (2011). 